\title{
A case of acute mercury vapour poisoning
}

\author{
C. J. EASTMOND \\ M.B., Ch.B., M.R.C.P. \\ S. HolT \\ M.B., Ch.B.
}

Liverpool Royal Infirmary. Liverpool L3 5PU

\begin{abstract}
Summary
A case is reported of a research chemist who was briefly exposed to a high concentration of mercury vapour and who developed symptoms of systemic poisoning, but who had a normal urinary excretion of mercury. This latter is not considered to refute the diagnosis. The literature is briefly reviewed.
\end{abstract}

\section{Introduction}

Mercury poisoning has been recognized for over a century. Evans' (1962) report of poisoning due to chronic exposure to mercury vapour in industry is well known. Polson and Tattersall (1969) have described other circumstances including the ingestion of mercurous and mercuric chlorides, the subcutaneous, intravenous and intra-arterial injection of elemental mercury and acute exposure to mercury vapour. Chronic mercury poisoning results in (a) exczssive salivation, the saliva having a foul odour and usually accompanied by swelling, reddening and tenderness of the lips, gums and tongue or whitening of the tongue followed by blistering, (b) an irregular tremor, not so fine as in thyrotoxicosis, and accompanied by irregular jerking movements commencing in the fingers and spreading to the face and tongue and (c) a tendency to sudden outbursts of anger interspersed with periods of timidity (erethism). Drowsiness, depression, loss of memory and insomnia may occur. Acute mercury poisoning on the other hand produces very different effects and those described in most accounts relate to the ingestion of the salts. There is prompt salivation and a sensation of burning in the mouth, throat and gullet, colicky abdominal pain, nausea and vomiting, bloody diarrhoea and thirst due to dehydration. Renal tubular necrosis occurs and with small or moderate doses there is often an initial diuretic phase but larger doses result in oliguria. Proteinuria and microscopic haematuria occur. Acute elemental mercury poisoning by inhaling the vapour has been reported by Campbell (1948), Glass (1970), Haddad and Stenberg (1963), Hallee (1969) and Milne, Christophers and de Silva (1970) and in nearly all cases dyspnoea has been a

Correspondence: Dr C. J. Eastmond, Research Fellow, Department of Medicine, University of Liverpool, Ashton Street, P.O. Box 147, Liverpool L69 3BX. major symptom and some patients have died of acute respiratory failure. The period of exposure in these cases has been in the order of a number of hours.

The case we report is that of a 27-year-old male research chemist who was exposed over a very short period of time to a high concentration of mercury vapour.

\section{Case report}

The patient was working with a gas chromatograph (Fig. 1) in his laboratory, the oven temperature was approximately $300^{\circ} \mathrm{C}$ and the fan was operating. Whilst near the oven he accidentally broke the stem of the thermometer with his elbow. He removed the stem out of the top of the oven and, realizing it was broken, immediately opened the oven door to recover the bulb. Unfortunately the bulb had already fallen into the oven and when he opened the door he inhaled the fumes. He stated that a small number of mercury globules were present on the bottom of the oven.

At first he noticed no ill effects but about $1 \mathrm{hr}$ later he noticed a dry mouth and throat with a metallic taste and slight nausea. On the advice of his colleagues he presented himself at the casualty department, but did not feel particularly ill. In the casualty department he passed a large quantity of urine estimated at about 1.5-2 1 but unfortunately this was not measured or kept. Four hours later his nausea was worse and he noticed excessive salivation. At no time did he, or any of his attendants, note that he had any respiratory difficulties and a chest radiograph on admission was normal. He was also noted to have slight albuminuria and microscopic haematuria (Ward side room test with 'Labstix'). It was at this stage that he was considered clinically to have mercury poisoning and advice was sought from the Edinburgh Royal Infirmary Poisons Centre. On their advice treatment was commenced with intravenous fluids $-500 \mathrm{ml} 2$ hourly of alternate normal saline and $5 \%$ dextrose, and dimercaprol (BAL) $200 \mathrm{mg}$ 6 hourly i.m. The dose of dimercaprol was reduced to $200 \mathrm{mg} 12$ hourly the following day and on the sixth day, when he was asymptomatic, to $100 \mathrm{mg}$ 12 hourly. Daily urine tests showed no further albuminuria or haematuria. The blood urea and 


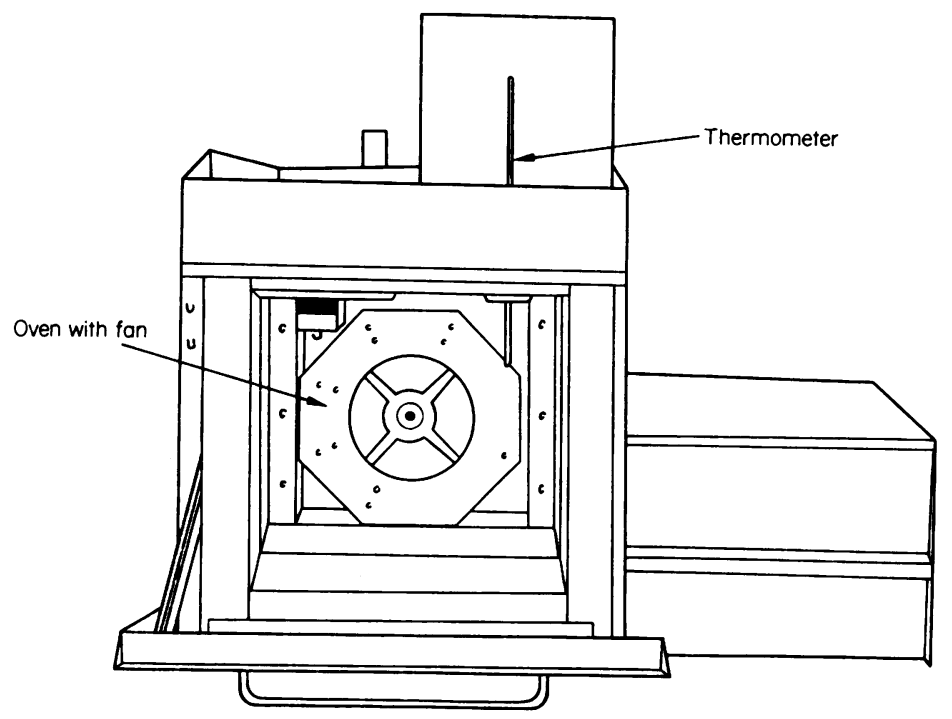

FIG. 1. Gas chromatograph used by the patient. Note the thermometer in the top and the fan at the back.

TABLE 1. 24-hr urinary mercury estimations

\begin{tabular}{cccc}
\hline Day & $\begin{array}{c}\text { Collection } \\
\text { period } \\
(\mathrm{hr})\end{array}$ & $\begin{array}{c}\text { Urine } \\
\text { volume } \\
\left(\mathrm{cm}^{3}\right)\end{array}$ & $\begin{array}{c}\text { Total } \\
\text { mercury } \\
(\mu \mathrm{g})\end{array}$ \\
\hline 1 & $11 \cdot 5$ & 4360 & $14 \cdot 9$ \\
2 & 24 & 7600 & $18 \cdot 2$ \\
3 & 24 & 4400 & $10 \cdot 3$ \\
\hline
\end{tabular}

electrolytes were normal, the haemoglobin $15.39 \mathrm{~g} \%$ and white cell count $10,200 / \mathrm{mm}^{3}$. The results of the urinary mercury estimations are shown in the table. Two months later his urinary mercury was $5 \mu \mathrm{g}$.

The oven was tested and it was shown that at $300^{\circ} \mathrm{C}$, concentrations of over $700 \mu \mathrm{g}$ of $\mathrm{Hg} / \mathrm{m}^{3}$ of air were obtained despite repeated attempts to decontaminate it and it had to be scrapped.

\section{Discussion}

The urinary concentration of mercury in previously reported cases have been in excess of $300 \mu \mathrm{g} / 1$ and it has generally been considered that levels less than this have no significance, but this value relates to studies performed by Buckell et al. (1946) and Lane (1954) following chronic exposure to mercury vapour. Even so, such high levels have been attained where exposure to high concentrations of mercury vapour has lasted a number of hours and this is in contradistinction to the case we report. Hallee (1969) reported on a family exposed to mercury vapour overnight and the urinary mercury levels in some of those with symptoms, i.e. nausea and ptyalism, were within what would be considered normal limits for chronic exposure. All these cases were treated with dimercaprol as was our patient. It is our opinion that this patient did have, as did Hallee's patients, acute mercury vapour poisoning, but without any demonstrable effect on the lung tissues, despite the low urinary mercury levels. It must be remembered that if dimercaprol is to be effective it must be administered as soon as possible after exposure to the poison so that the damaged enzymes systems have the best chance of recovery and thereby so has the patient. It must also be given frequently so as to maintain excess free dimercaprol in the body because the chelate is unstable, tending to release the metal. It would seem reasonable, therefore, to recommend intensive treatment to any patient exposed to mercury vapour on the least suspicion of acute systemic poisoning and to continue such treatment even in the absence of excessive urinary mercury levels.

\section{Acknowledgments}

We wish to thank Professor D. A. Price-Evans for permission to report on this patient who was under his care and Dr $O$. P. Edmonds for supplying information with regard to the testing of the oven. Also the Edinburgh Royal Infirmary Poisons Centre for their advice.

\section{References}

Buckell, M., Hunter, D., Milton, R. \& Perry, K.M.A. (1946) Chronic mercury poisoning. British Journal of Industrial Medicine, 3, 55.

CAmprell, J.S. (1948) Acute mercurial poisoning by inhalation of metallic vapour in an infant. Canadian Medical Association Journal, 58, 72.

Evans, D.M. (1962) Mercury poisoning. British Medical Journal, i, 1458. 
Glass, W.I. (1970) Mercury fume fever. New Zealand Medical Journal, 71, 297.

HAdDAD, J.K. \& Stenberg, E. (1963) Bronchitis due to acute mercury inhalation. American Review of Respiratory Diseases, 88, 543.

HALlEE, J.T. (1969) Diffuse lung disease caused by inhalation of mercury vapour. American Review of Respiratory Diseases, 99, 430.
LANE, R.E. (1954) Laboratory investigations in suspected industrial poisoning. British Medical Journal, i, 978.

Milne, J., Christophers, A. \& De Silva, P. (1970) Acute mercurial pneumonitis. British Journal of Industrial Medicine, 27, 334.

Polson, C.N. \& Tattersall, R.N. (1969) Clinical Toxicology, 2nd edn, p. 217. Pitman Medical, London. 